\title{
Spray Granulation
}

National Cancer Institute

\section{Source}

National Cancer Institute. Spray Granulation. NCI Thesaurus. Code C113013.

Granulation involving the atomization of a slurry of fine particles that are bound as they are suspended and conveyed by a flowing hot gas stream, resulting in dry granules suitable for filling or compression. 